\title{
Exocannabinoids effect on in vitro bovine oocyte maturation via activation of AKT and ERK1/2
}

\author{
A P López-Cardona ${ }^{1,2}$, M J Sánchez-Calabuig ${ }^{1}$, P Beltran-Breña ${ }^{1}$, N Agirregoitia ${ }^{3}$, D Rizos ${ }^{1}$, \\ E Agirregoitia ${ }^{3, *}$ and A Gutierrez-Adán ${ }^{1, *}$ \\ ${ }^{1}$ Departamento de Reproducción Animal, INIA, Madrid, Spain, ${ }^{2}$ G.I. Biogénesis, Universidad de Antioquia, Medellín, \\ Colombia, and ${ }^{3}$ Department of Physiology, Faculty of Medicine and Dentistry UPV/EHU, Leioa, Bizkaia, Spain \\ Correspondence should be addressed to Á P López-Cardona; Email: angeladir7@gmail.com
}

*(E Agirregoitia and A Gutierrez-Adán contributed equally to this work)

\begin{abstract}
Endocannabinoids are known to mediate practically all reproductive events in mammals; however, little is known about their role in oocyte maturation. Through RT-PCR and immunocytochemistry, this study confirms the presence of CB1 and CB2 cannabinoid receptors in bovine oocytes and shows how exposure to the exogenous cannabinoids HU-210 and THC during their in vitro maturation (IVM) activates the phosphorylation of AKT and ERK1/2 proteins associated with the resumption of meiosis. Although supplementation with HU-210 or THC during IVM did not increase blastocyst yields, the expression of interferon tau (IFN $\tau$ ) and gap junction alpha-1 protein (GJA1) was enhanced at the blastocyst stage. Our data suggest that cannabinoid agonists may be useful IVM supplements as their presence during oocyte maturation upregulates the expression in blastocysts of key genes for embryo quality.

Reproduction (2016) 152 603-612
\end{abstract}

\section{Introduction}

The molecular mechanisms responsible for oocyte maturation are not fully understood and various molecules seem capable of modulating this process. Among these molecules, an important role of the cannabinoid compounds, fatty acid derivatives that exert their effects by binding to membrane cannabinoid receptor 1 (CNR1 or CB1) and cannabinoid receptor 2 (CNR2 or CB2), both Gi/o protein-coupled receptors, has been proposed (Devane et al. 1988, Matsuda et al. 1990). Many of the components of the endocannabinoid system have been identified in the ovary, oocyte, granulosa cells and embryos of mice, rats and humans (Wang et al. 2004, El-Talatini et al. 2009a, Peralta et al. 2011, López-Cardona et al. 2014, Agirregoitia et al. 2015, Miller et al. 2016). In effect, the best characterized endocannabinoid, anandamide (AEA), is present in human follicular fluid and its concentrations rise during oocyte maturation (Schuel et al. 2002, Wang et al. 2003, El-Talatini et al. 2009b). A recent study in cattle has identified AEA in oviductal fluid with highest concentrations found during the periovulatory period (Gervasi et al. 2013). However, the presence of AEA receptors on the oocyte has not yet been reported. In addition, cell signalling exerted by cannabinoids and the signalling that occurs when oocyte meiosis resumes both in humans (Peralta et al. 2011) and mice (Paria et al. 1995, Schmitt \& Nebreda 2002) share several similar features.

In human clinical practice, immature oocytes harvested from antral ovarian follicles can be in vitro matured (IVM) in culture media supplemented with different molecules to promote maturation. Despite disappointingly low embryo production and pregnancy rates offered by this technique (Barnes et al. 1995, Barnes et al. 1996, Cha et al. 2000), IVM could be the only option for women intolerant to gonadotropins (Cha et al. 2000) wishing to undergo in vitro fertilization (IVF). Before any clinical trial is designed to improve IVM, research is needed in an animal model similar to the human model such as cow (Menezo \& Herubel 2002). Humans and cows are single ovulators and show close similarity in ovarian function and oocyte characteristics (Van Hoeck et al. 2011). Indeed, bovine oocyte maturation shares features with the human model in terms of ovarian follicular dynamics and endocrine control (Menezo \& Herubel 2002, Campbell et al. 2003). Some authors even proposed the bovine maturation model as a reliable surrogate method to screen for toxic agents or metabolic studies in human oocytes (Van Hoeck et al. 2011, Beker van Woudenberg et al. 2012, Santos et al. 2014). 
Despite this useful model, investigations to date examining the role of endocannabinoids in bovine reproduction events have mainly focused on the sperm physiology and sperm-oviduct interaction. These efforts have revealed that AEA induces sperm capacitation through CB1 and the transient receptor potential vanilloid 1 (TRPV1) activation, and modulates sperm release from the oviductal reservoir (Gervasi et al. 2011, 2016). Moreover, recently it has been demonstrated that endocannabinoid signalling governs sperm activation via sex hormone progesterone (Miller et al. 2016), a non-genomic signal that is also required for oocyte maturation (Revelli et al. 1998). Based on the above discussion, the aim of this study is to confirm the presence of cannabinoid receptors in bovine oocytes and whether the presence of exogenous cannabinoids, such as HU-210 ((6aR,10aR)-3-(1,1dimethylheptyl)-6a,7,10,10a-tetrahydro-1-hydroxy-6,6dimethyl-6H-dibenzo[b,d]pyran-9-methanol) or THC $(\Delta 9$-tetrahydrocannabinol), in the maturation medium activates pathways involved in oocyte maturation like protein kinase B (also known as AKT) and extracellular signal-regulated kinase (ERK1/2) phosphorylation and thus improves in vitro blastocyst quality without compromising embryo development.

\section{Materials and methods}

Unless otherwise stated, all chemicals and media were purchased from Sigma Chemical Co.

\section{Isolation and in vitro maturation of cumulus-oocyte complexes}

Immature cumulus-oocyte complexes (COCs) were obtained by aspirating follicles $(2-8 \mathrm{~mm})$ from the ovaries of matured heifers and cows collected at slaughter from a local abattoir. COCs (homogenous cytoplasm and intact cumulus cells) were matured in four-well dishes (Nunc, Roskilde, Denmark) in 500 $\mu \mathrm{L}$ TCM-199 maturation medium, supplemented with $10 \%(\mathrm{v} / \mathrm{v})$ foetal calf serum (FCS) and $10 \mathrm{ng} / \mathrm{mL}$ epidermal growth factor (EGF) in groups of 50 COCs per well for $24 \mathrm{~h}$ at $38.5^{\circ} \mathrm{C}$ under an atmosphere of $5 \% \mathrm{CO}_{2}$ in air with maximum humidity (Rizos et al. 2002).

\section{IVM supplementation with cannabinoid agonists}

COCs were co-incubated with the cannabinoid agonists HU-210 and THC (concentration of $100 \mathrm{nM}$ in $0.1 \%$ DMSO) in maturation medium, according to prior optimization experiments (López-Cardona et al. 2014). COCs incubated with and without DMSO served as controls. A total of five replicates were carried out.

\section{In vitro fertilization}

After $24 \mathrm{~h}$ of maturation, the in vitro matured COCs were washed twice in fertilization medium before being transferred in groups of 50 to the wells of four-well plates each containing $250 \mu \mathrm{L}$ fertilization medium (FERT-TALP medium (Merck) supplemented with $25 \mathrm{mM}$ bicarbonate, $22 \mathrm{mM}$ sodium lactate, $1 \mathrm{mM}$ sodium pyruvate, $6 \mathrm{mg} / \mathrm{mL}$ fatty acid-free bovine serum albumin (BSA) and $10 \mathrm{mg} / \mathrm{mL}$ heparin). Frozen bull semen was thawed in a water bath at $37^{\circ} \mathrm{C}$ for $50 \mathrm{~s}$ and motile spermatozoa separated on a density gradient (BoviPure, Nidacon International, Mölndal, Sweden), centrifuged and re-suspended in fertilization medium. Then, $250 \mu \mathrm{L}$ of this suspension were added to each fertilization well to obtain a final concentration of $1 \times 10^{6}$ spermatozoa $/ \mathrm{mL}$. Gametes were co-incubated under $5 \% \mathrm{CO}_{2}$ in air at maximum humidity for $20 \mathrm{~h}$ at $38.5^{\circ} \mathrm{C}$.

\section{In vitro culture}

Presumptive zygotes were denuded by gentle vortexing for $3 \mathrm{~min}$, washed twice in phosphate buffer saline (PBS) supplemented with 3\% BSA and cultured in groups of 25 in $25 \mu \mathrm{L}$ droplets of synthetic oviduct fluid (SOF) (Holm et al. 1999) supplemented with 5\% FCS under mineral oil at $38.5^{\circ} \mathrm{C}$ in an atmosphere of $5 \% \mathrm{CO}_{2}, 5 \% \mathrm{O}_{2}$ and $90 \% \mathrm{~N}_{2}$, with maximum humidity. Cleavage rate was recorded on day 2 (48 h post insemination) and cumulative blastocyst yield was recorded on days 7,8 and 9 post insemination.

\section{Meiotic progression of bovine oocytes undergoing IVM with exogenous cannabinoids}

In order to determine the impact of $\mathrm{HU}-210$ and $\mathrm{THC}$ on germinal vesicle (GV) breakdown, COCs from both experimental groups and control with DMSO at 2, 4, 6, 8 and $12 \mathrm{~h}$ of IVM ( $n=30$ per time point and group in three independent replicates) were used as described previously (Khatir et al. 1998). Briefly, COCs were partially denuded by vortexing during $3 \mathrm{~min}$ in $0.1 \%$ of hyaluronidase (Sigma H3506) and fixed in 4\% paraformaldehyde (Panreac, Barcelona, Spain) for $20 \mathrm{~min}$. Then were washed twice in PBS and incubated in PBS containing $10 \mu \mathrm{g} / \mathrm{mL}$ Hoechst 33342 for $15 \mathrm{~min}$. Oocytes were then placed in glass slides and squashed with coverslip in order to visualize the nuclear stage under microscopy (Nikon Optiphot-2) (Coy et al. 2008).

\section{Immunofluorescence}

Pools of 20 COCs were obtained from DMSO group for the different maturation stages: The first group was immediately fixed after removal from the follicle representing the GV stage in $100 \%$ of oocytes. The second and third groups were removed from maturation medium at $12 \mathrm{~h}$ for metaphase I (MI) and $24 \mathrm{~h}$ for metaphase II (MII) stages, representing 94 and $90 \%$ respectively of total oocytes evaluated. CB1 and CB2 receptors were immunocytochemically localized as described previously (Peralta et al. 2011). In brief, COCs were partially denuded and washed in PBS supplemented with $1 \%$ polyvinyl alcohol (PVA) and fixed in $4 \%$ paraformaldehyde for $10 \mathrm{~min}$ at room temperature. Next, they were permeabilized by incubation in PBS with $10 \%(\mathrm{v} / \mathrm{v})$ FCS and $1 \%$ Triton X-100 for $45 \mathrm{~min}$ at 
room temperature. After permeabilization, oocytes were incubated overnight at $4^{\circ} \mathrm{C}$ in PBS containing $1 \%$ PVA, $5 \%$ FCS and 1:100 rabbit polyclonal anti-cannabinoid CB1 receptor (Cayman Chemical) and anti-cannabinoid CB2 receptor (Cayman Chemical) antibodies. Following incubation, oocytes were washed twice in PBS with $1 \%$ PVA and incubated in PBS supplemented with 5\% FCS and 1:250 goat polyclonal secondary antibody Alexa Fluor 488 (Molecular Probes) for $2 \mathrm{~h}$ at room temperature followed by washing again three times in PBS - 1\% PVA. In all cases, nuclei were stained with Hoechst 33342 at a concentration of $0.01 \mathrm{mg} / \mathrm{mL}$ during the second wash to determine the maturation stage of each oocyte (Gutierrez-Adan \& Pintado 2000). Finally, oocytes were mounted in microdrops with Fluoromount G (EMS, Hatfield, UK) and examined by confocal microscopy (Leyca TCS-SPE). Negative control were prepared using blocking peptide and omitting the primary antibody before adding the secondary antibody. To monitor AKT and ERK $1 / 2$ activation during oocyte maturation due to the presence of the cannabinoids, 20 oocytes were removed from the maturation medium at 0 , 5 and $30 \mathrm{~min}$, to evaluate the initial response, and $24 \mathrm{~h}$, to evaluate if the initial response was remaining in order to produce an effect in the mature oocyte, following the same protocol described previously. The primary rabbit polyclonal antibodies against phosphorylated AKT and phosphorylated ERK1/2 (Cell Signaling Technology) were used at 1:100 dilution, and the secondary antibody goat polyclonal Alexa Fluor 488 (Molecular Probes) was used at 1:250. Fluorescence of phosphorylated AKT and phosphorylated ERK1/2 were analysed by confocal microscopy (Leyca TCSSPE) and quantified using the ImageJ programme v. 1.45 (http://rsb.info.nih.gov/ij) (Huang et al. 2012). Fluorescence was evaluated separately in granulosa cells and oocytes. All experiments were performed in the same day, with the same method and using the same settings in the microscope to be able to compare the fluorescence among treatments. Data are expressed as a fold over vehicle phosphorylation.

\section{RNA extraction, reverse transcription PCR and real-time PCR ( $q P C R)$}

Gene expression was examined in oocytes and blastocysts as described previously (Bermejo-Alvarez et al. 2011). Pools of 20 oocytes were obtained for the maturation stages as performed for immunofluorescence: GV, MI and MII. For blastocysts, we used pools of 10 obtained on day 7 post-fertilization; three replicates of four samples per experimental group were carried out in both cases. Poly (A) RNA was extracted using the Dynabeads mRNA DIRECT Micro Kit (Ambion, Thermo Fisher Scientific Inc) following the manufacturer's instructions with minor modifications (Bermejo-Alvarez et al. 2010). After 10 min of incubation in lysis buffer with Dynabeads, poly(A) RNA attached to the Dynabeads was extracted with a magnet and washed twice in washing buffer A and washing buffer B. RNA was eluted with Tris- $\mathrm{HCl}$. After extraction, RT reaction was carried out following the manufacturer's instructions (Epicentre Technologies Corp, Madison, WI, USA) using poly(T) primers, random primers and MMLV High Performance Reverse Transcriptase enzyme in a total volume of $40 \mu \mathrm{L}$, to prime the $\mathrm{RT}$ reaction and produce cDNA. Tubes were heated to $70^{\circ} \mathrm{C}$ for $5 \mathrm{~min}$ to denature the secondary RNA structure and then the RT mix was completed with the addition of 50 units of reverse transcriptase. Next, the tubes were incubated at $25^{\circ} \mathrm{C}$ for $10 \mathrm{~min}$ to promote the annealing of random primers, at $37^{\circ} \mathrm{C}$ for $60 \mathrm{~min}$ to allow the RT of RNA and, finally, at $85^{\circ} \mathrm{C}$ for $5 \mathrm{~min}$ to denature the enzyme. Four cDNA samples were performed per experimental group. All qPCR analyses were run in the following conditions: $95^{\circ} \mathrm{C}$ for $3 \mathrm{~min}, 35$ cycles at $94^{\circ} \mathrm{C}$ for $15 \mathrm{~s}, 54^{\circ} \mathrm{C}$ for $25 \mathrm{~s}$ and $72^{\circ} \mathrm{C}$ for $20 \mathrm{~min}$, followed by a final extension step at $72^{\circ} \mathrm{C}$ for $5 \mathrm{~min}$. qPCR analyses were carried out in duplicate in the Rotor Gene 6000 real-time cycler (Corbett Research, Sydney, Australia) by adding $5 \mathrm{ng}$ of each sample to the PCR mix (GoTaq qPCR Master Mix, Promega) containing the specific primers selected to amplify the selected genes. The comparative cycle threshold (CT) method was used to quantify expression levels. Values were normalized to the endogenous control (housekeeping gene: histone $\mathrm{H} 2 \mathrm{afz}$ ). According to the comparative CT method, the $\triangle \mathrm{CT}$ value was determined by subtracting the HK mean CT value for each sample from each gene CT value of the sample. The calculation of $\Delta \Delta C T$ involved using the highest treatment $\Delta \mathrm{CT}$ value, that is, the treatment with the lowest target expression, as an arbitrary constant to subtract from all other $\Delta \mathrm{CT}$ sample values. Fold changes in the relative gene expression of the target were determined using the formula 2- $\triangle \Delta C T$ (Murray et al. 2007). The primers used for qPCR are as follows: $\mathrm{H} 2 \mathrm{~A}$ histone family, member $\mathrm{Z}$ (H2AFZ), cannabinoid receptor type 1 (CNR1), cannabinoid receptor type 2 (CNR2), BCL2-associated X protein (BAX), BCL2-like 1 (BCL2), tumour protein p53 (TP53), glutathione peroxidase 1 (GPX1), superoxide dismutase 2, mitochondrial (SOD2), DNA cytosine-5-methyltransferase 3 alpha (DNMT3A), insulin-like growth factor 2 receptor (IGF2R), solute carrier family 2 (facilitated glucose 1 transporter), member (SLC2A1), glyceraldehyde 3-phosphate dehydrogenase $(G A P D H)$, POU class 5 homeobox 1 (Oct3/4) (POU5F1), interferon tau $(I F N \tau)$ and gap junction protein, alpha 1 (former CX43) (GJA1). Primer sequences and approximate sizes of the amplified fragments of all transcripts are provided in Table 1 . The presence or absence of $m$ RNA for $C B 1$ and $C B 2$ was established in maturation stages; H2AFZ was used as the housekeeping gene. Foetal bovine organs like brain and spleen, obtained from the slaughterhouse were used as positive control for expression of CNR1 and CNR2 respectively. RT-PCR with total RNA without reverse transcriptase was used as negative control.

\section{Data analysis}

All statistical tests were performed using the software package SigmaStat 3.5 (Jandel Scientific, San Rafael, CA, USA). Fluorescence intensity of phosphorylated AKT and phosphorylated ERK1/2, cleavage rates, blastocyst yields and relative mRNA abundances for candidate genes were compared by one-way ANOVA $(P<0.05)$ followed by multiple pair-wise comparisons using the Tukey method. 


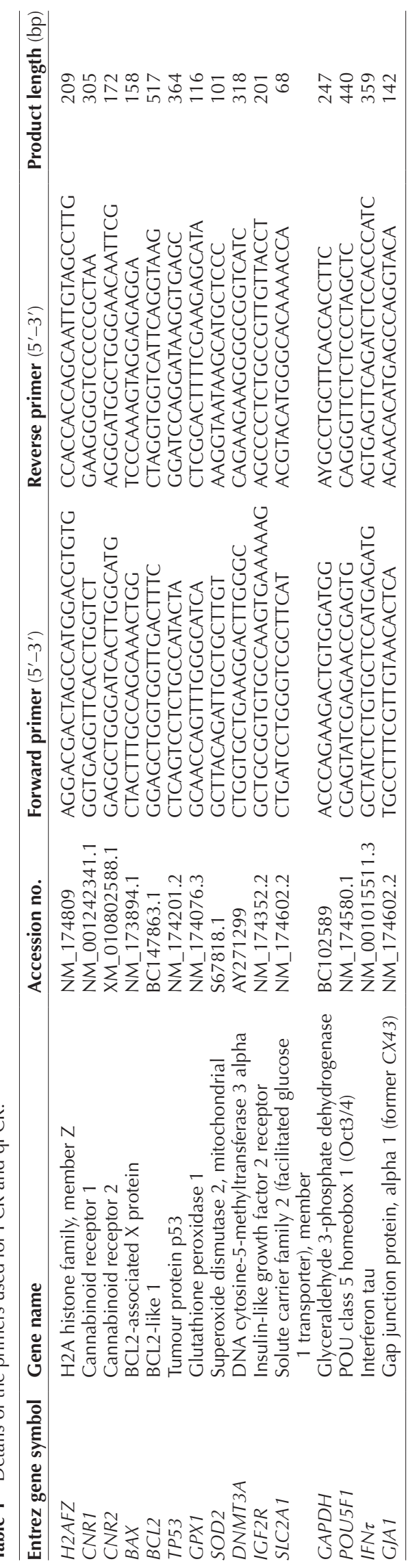

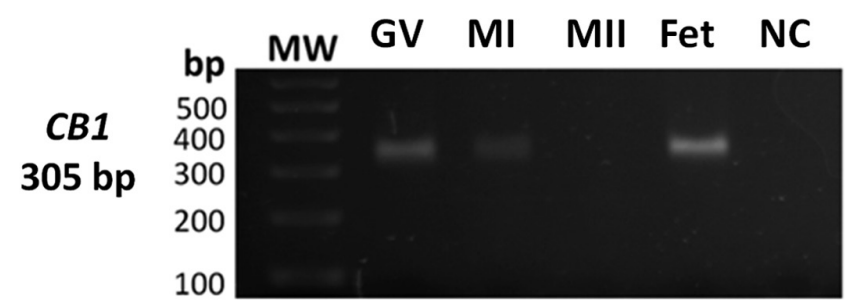
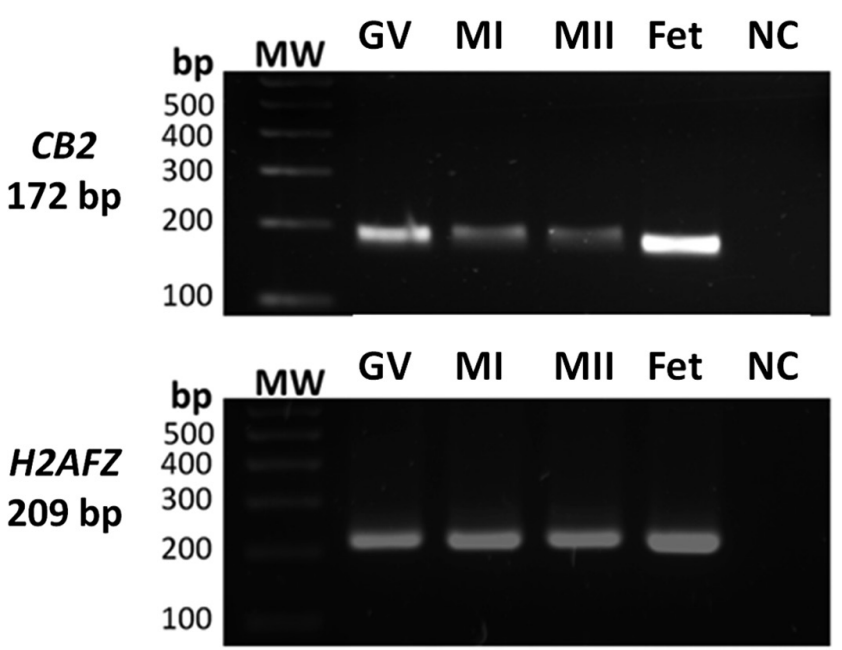

Figure $1 C B 1$ and $C B 2$ receptor expression during the nuclear maturation of bovine oocytes. CB1 (305 bp), CB2 (172 bp) and H2AZF (209 bp) mRNAs in stage GV, MII and MII oocytes matured in vitro. Foetus of bovine species (Fet) served as positive control for CB1 and $C B 2$, brain and spleen respectively. To validate the RT-PCR procedure, reactions with total RNA and without reverse transcriptase were used as negative control $(\mathrm{NC})$. Molecular weights (MW; bp) are indicated on the left. $n=3$; a representative RT-PCR experiment is shown.

\section{Results}

Expression dynamics and immunolocalization of the cannabinoid receptors $C B 1$ and $C B 2$ during bovine oocyte maturation

During the in vitro maturation of bovine oocytes, $C B 1$ mRNA was detected in GV and MI oocytes but not MII stage oocytes. In contrast, the CB2 transcripts appeared in oocytes in all stages following the resumption of meiosis (GV, MI and MII) (Fig. 1).

Immunofluorescence analysis revealed the presence of both CB1 and CB2 receptor proteins during IVM (Fig. 2). CB1 was evenly distributed in GV stage oocytes yet adopted a peripheral location after the resumption of meiosis in the Ml stage and a more evident peripheral location in MII. In contrast, staining for the CB2 receptor was homogeneous across the cell in all the stages examined.

\section{Exposure to HU-210 or THC during bovine oocyte maturation modifies subsequent AKT and ERK1/2 phosphorylation patterns}

No differences were found among control groups, with or without $0.1 \%$ DMSO, in phosphorylation pattern of 
A
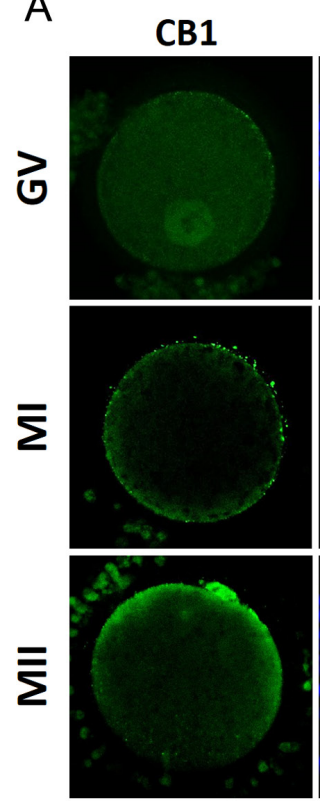

DNA
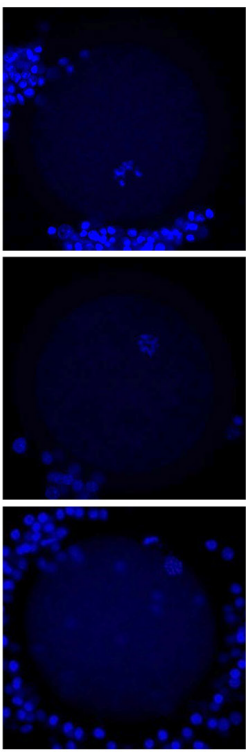

Merge
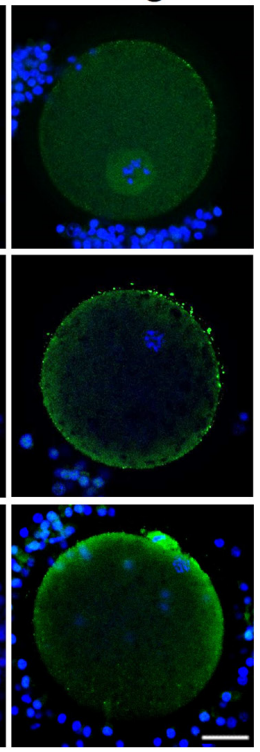

B
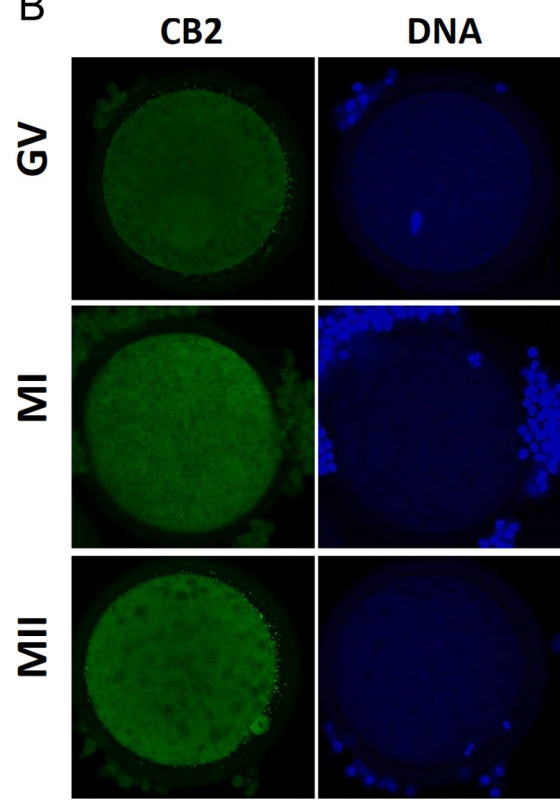

Merge
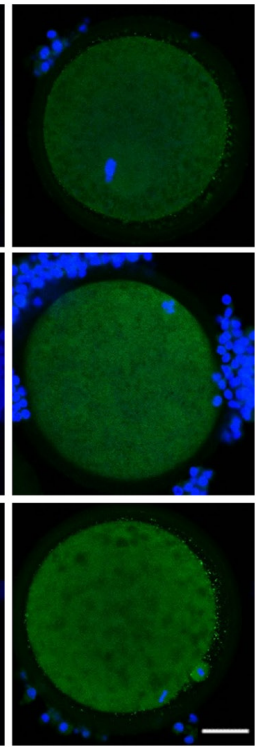

Figure 2 CB1 and CB2 immunolocalization during the nuclear maturation of bovine oocytes. (A) Distribution of CB1 (shown in green) during the in vitro maturation of oocytes at the stages germinal vesicle (GV), metaphase I (MI) and metaphase II (MII). (B) Distribution of CB2 (green) during in vitro maturation of oocytes at the stages GV, MI and MII. Hoechst-labelled DNA (shown in blue). Scale bar represents $20 \mu \mathrm{m}$.

$A K T$ and $E R K 1 / 2$ proteins, embryo development (day 9: $24.6 \pm 2.6 \%$ vs $27.3 \pm 4.7 \%$ respectively) and blastocysts gene expression. Based on this and on the fact that DMSO was the vehicle for both drugs, it was considered the most appropriate group to be used as a control.

In Fig. 3 it may be observed that no phosphorylation signal was produced for any of the proteins examined before the addition of the drugs $\left(0^{\prime}\right)$. In contrast, while staining for phosphorylated AKT was negligible in oocytes exposed to vehicle (DMSO), after $5 \mathrm{~min}$ of treatment with either HU-210 or THC, a clear AKT phosphorylation signal was detected in granulosa cells along with weaker staining in the oocyte. After $30 \mathrm{~min}$, this staining pattern remained fairly stable. However, after $24 \mathrm{~h}$ of incubation (the time required for bovine oocyte maturation), pAKT was homogenously distributed across the oocyte and its signal in the granulosa cells diminished in both the HU-210 and THC groups while the absence of pAKT staining persisted in the vehicle group. The pAKT phosphorylation pattern at $24 \mathrm{~h}$ was, nevertheless, weaker in the HU-210 than THC group (Fig. 3A).

ERK1/2 phosphorylation patterns (Fig. 3B) in response to $5 \mathrm{~min}$ of treatment with the cannabinoid agonists included a pERK1/2 signal in granulosa cells, which was weaker in the vehicle group, and some signal across the oocyte in both the HU-210 and THC groups. However, after 30 min of incubation, pERK1/2 staining in the oocyte significantly differed between the vehicle and treatment groups whereas after $24 \mathrm{~h}$, ERK1/2 phosphorylation similarly diminished in granulosa cells and increased over the oocyte in all the study groups (Fig. 3B).

\section{Changes in velocity of meiotic progression of bovine oocyte's exposure to HU-210 or THC}

To analyse if the exocannabinoids have some effect on oocyte nuclear maturation we fixed oocyte after 0,2 , 4, 6, 8 and $12 \mathrm{~h}$ of IVM with media supplemented with HU-210 or THC. Oocytes nuclear stage was classified in GV, GVBD, PMI, MI and MII. As we can see in Fig. 4A, at $0 \mathrm{~h}$ all the oocytes were in GV stage, and after $2 \mathrm{~h}$ of IVM a higher percentage of GVDB was found when we used exogenous cannabinoids compared with the control group. After $6 \mathrm{~h}$ of IVM the majority of the oocytes were at PMI, but no differences were observed among treatments. Also after $8 \mathrm{~h}$ of IVM, all groups reached $\mathrm{Ml}$ (Fig. 4C) at the same time, however, after $12 \mathrm{~h}$ of maturation a higher percentage of MII stage was found in both experimental groups compared with control (Fig. 4D).

\section{Blastocyst rate and gene expression of embryo produced from oocytes matured in the presence of HU-210 or THC}

We next examined whether exposure to the cannabinoids during oocyte maturation would have impacts on fertilization and/or subsequent embryo development and quality. To first establish the effects of the cannabinoids during oocyte maturation, immature COCs were cultured in vitro for $24 \mathrm{~h}$ in the presence or absence of $\mathrm{HU}-210$ or THC. The cannabinoids were then removed from the culture medium and IVF experiments performed on these matured COCs. Incubation with $100 \mathrm{nM}$ of HU-210 or THC had no significant effects on the rates 


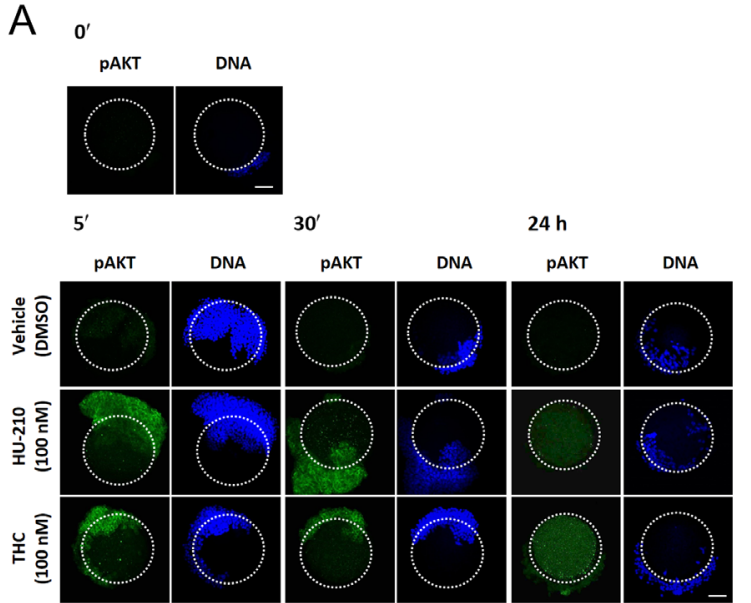

$B_{0}$

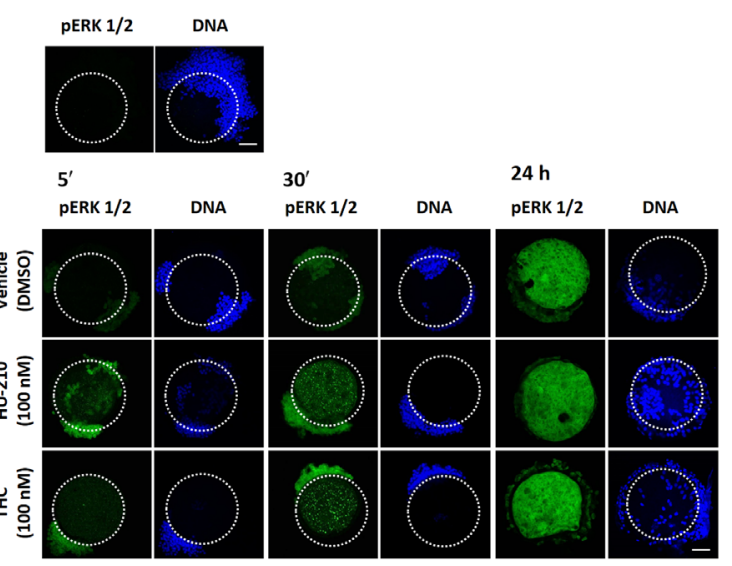

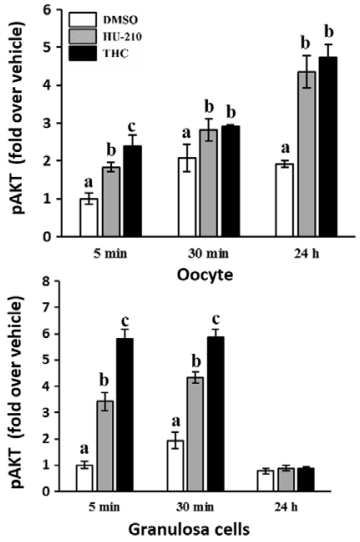

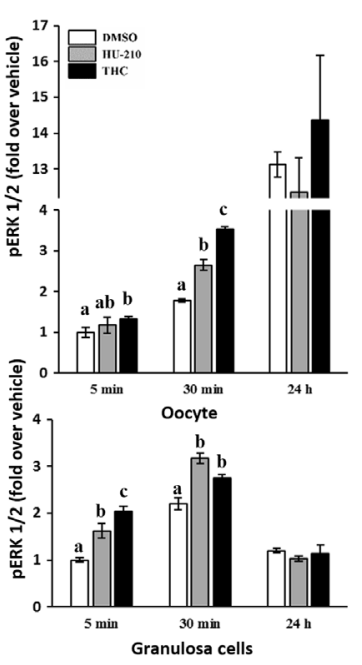

Figure $3 \mathrm{AKT}$ and ERK1/2 activation in response to HU-210 or THC supplementation during in vitro bovine oocyte maturation. Immature GV oocytes were cultured in the presence of $100 \mathrm{nM}$ of each cannabinoid. The activation state of AKT or ERK1/2 was evaluated at $0,5,30 \mathrm{~min}$ and $24 \mathrm{~h}$ (the time needed for bovine oocyte maturation). (A) Phosphorylation state of AKT in response to the presence of $\mathrm{HU}-210$ or THC during oocyte maturation. (B) Phosphorylation state of ERK1/2 (pERK1/2) in response to the presence of HU-210 or THC during oocyte maturation. Images depict Alexa488-labelled antigens in green. Hoechst-labelled DNA appears in blue, scale bar represents $20 \mu \mathrm{m}$. Normalized data was expressed as a fold over vehicle phosphorylation for both proteins and was analysed separately in oocyte and granulosa cells. Significant differences between treatments are indicated with different letters ${ }^{\mathrm{a}, \mathrm{b}, \mathrm{c}} ;(P<0.05)$. recorded of cleaved embryos or blastocysts on days 7,8 and 9 post-IVF $(P>0.05$, Table 2$)$. To determine effects on embryo quality, we examined the expression of mRNAs for key genes related to apoptosis, oxidative stress, methylation, metabolism, cell junctions, pluripotency and implantation. Expression patterns of the majority of these genes did not differ in embryos arising from oocytes maturated in the presence of THC or HU-210 compared with control (Fig. 5). However, we observed the upregulation in the treatment vs control groups $(P<0.05)$ of the genes GJA1, also known as connexin 43 , involved in cell signalling related to the formation of cell junctions, and IFN $\tau$ involved in cell signalling related to recognition for implantation. The expression of IFN $\tau$ was similarly upregulated in the HU-210 and THC groups while, although GJA1 expression was also upregulated in both treatment groups $(P<0.01$, Fig. 5), this upregulation was significantly more pronounced in the THC group compared with the HU-210 group $(P<0.01$, Fig. 5).

\section{Discussion}

The findings of our study indicate that, when present during the in vitro maturation of bovine oocytes, the exocannabinoids $\mathrm{HU}-210$ and THC are able to modulate $\mathrm{AKT}$ and $\mathrm{ERK} 1 / 2$ phosphorylation. In addition to this effect we observed that the expression of two genes related to embryo quality (IFN $\tau$ and GJA1) was upregulated.

Exocannabinoids such as HU-210 and THC are pharmacologically more stable than endocannabinoids (such as AEA) and are thus the preferred choice for pharmacology assays (Pertwee 2006). Our selection of the bovine oocyte model was based on the fact that a high percentage of oocytes mature in vitro compared with other model species (Sirard et al. 2006, Moussa et al. 2015), and their similarities with human oocytes in terms of metabolic requirements, genome activation, interactions with the culture medium and early embryo development (Menezo et al. 2000, Van Hoeck et al. 2011). 

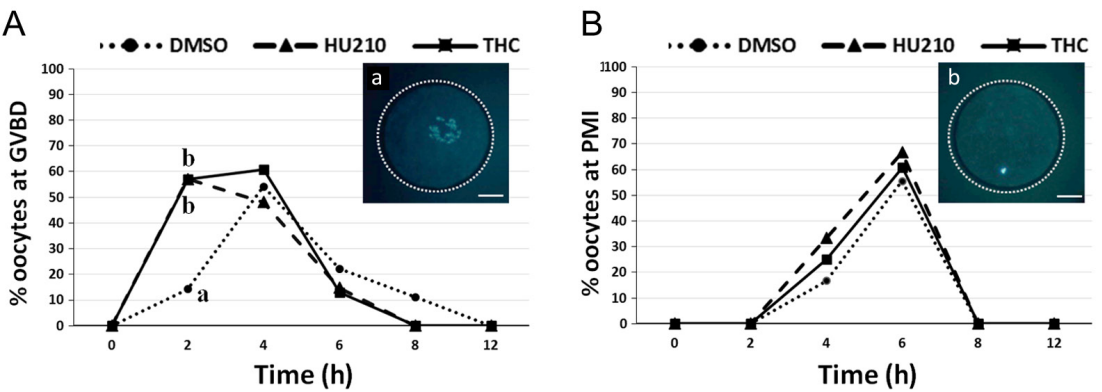

Figure 4 Changes in nuclear status of oocytes throughout maturation. Results are expressed as percentage of oocytes at each stage of maturation at each time point. To simplify the analysis, four stages were chosen: germinal vesicle breakdown (A) (GVBD), defined by the absence of visible nuclear membrane;

(B) pro-metaphase I stage (PMI), (C) defined by
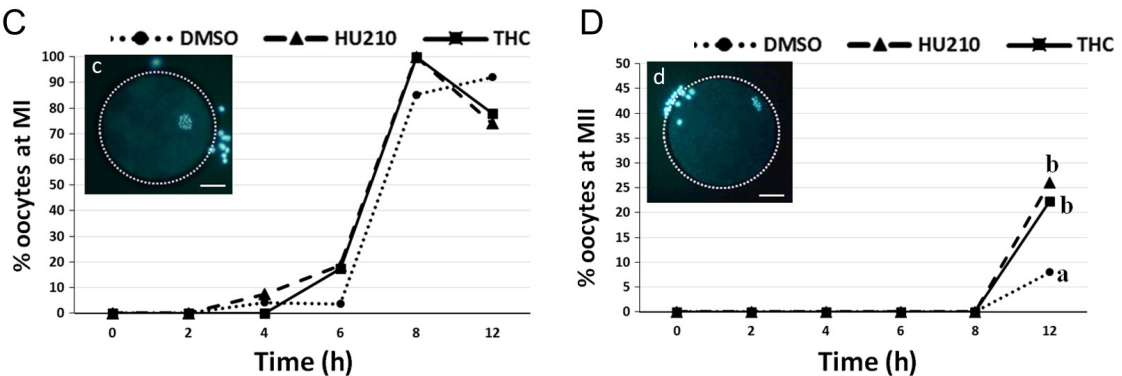
chromatin condensation; metaphase I stage (MI), (D) material with individual chromosomes and metaphase II stage (MII). Significant differences among treatments at the same time are indicated with different letters $^{\mathrm{a}, \mathrm{b}} ;(P<0.05)$. Representative photomicrographs are shown. Scale bar represents $20 \mu \mathrm{m}$. (a) Representative image of GVBD, (b) representative image of oocyte with $\mathrm{PMI}$, (c) representative image of $\mathrm{MI}$, (d) representative image of oocyte with MII.

Maternal RNA is critical for an efficient meiotic cell cycle and ensuing fertilization and embryo development. Despite this, oocytes suffer a maternal RNA loss of around 20\% during their maturation (Chen et al. 2013, Mehlmann 2013). This study detected the dramatic degradation of CB1 mRNA in MII oocytes, as observed in the mouse model (López-Cardona et al. 2014). This event could play a critical role in acquiring oocyte competence for fertilization and subsequent embryo development. At the protein level, we noted changes only in the localization of the CB1 receptor, which moved towards the periphery of the oocyte as meiosis progressed, whereas the localization of the CB2 receptor remains unchanged. Given that receptors need to reach the cell surface in order to act (Cahill et al. 2007) (according to G-protein-coupled receptor theory), CB1 could be the active receptor during oocyte maturation, as reported for the mouse and human models (Peralta et al. 2011, López-Cardona et al. 2014), suggesting that the endocannabinoid system, acting via CB1, is a conserved mechanism in mammalian oocyte maturation.

Oocyte maturation involves the activation of various signal transduction pathways, including PI3K/AKT or
MAPK pathways (Schmitt \& Nebreda 2002, Cecconi et al. 2012, Conti et al. 2012), which culminate in the activation of maturation-promoting factor (MPF), a complex consisting of cdc2 kinase and cyclin B (Schmitt \& Nebreda 2002). Myelin transcription factor 1 (MYT1), the major inhibitory kinase of the MPF complex, is phosphorylated and inhibited by AKT activity, thus promoting the resumption of meiosis (Okumura et al. 2002). In effect, studies in mouse and rat oocytes have shown that AKT activity blockage leads to a significant reduction in cdc2 activity and delayed meiosis resumption (Kalous et al. 2009) and that LH treatment induces higher phosphorylation levels of AKT (Carvalho et al. 2003). Cow oocytes are dependent on active AKT for successful MI/MII transition (Tomek \& Smiljakovic 2005). Our results indicate that exposure of these oocytes to HU-210 or THC during their in vitro maturation enhances AKT phosphorylation both in granulosa cells and within the oocyte.

The capacity of FSH or EGF to activate ERK $1 / 2$ is well documented (Gonzalez-Robayna et al. 2000, Wayne et al. 2007). In cow, such phosphorylated ERK1/2 is necessary for meiosis resumption (Levesque \& Sirard 1995, Su et al. 2003). Here, we show that cannabinoids

Table 2 Cleavage rates (D2) and blastocyst yields at day 7 (D9), 8 (D8) and 9 (D9) with and without cannabinoids supplementation in IVM.

\begin{tabular}{|c|c|c|c|c|c|c|c|c|c|}
\hline \multirow[b]{3}{*}{ Group } & \multirow[b]{3}{*}{$n$} & \multirow{2}{*}{\multicolumn{2}{|c|}{$\begin{array}{c}\text { Embryo cleavage } \\
\mathrm{D} 2\end{array}$}} & \multicolumn{6}{|c|}{ Blastocyst yield } \\
\hline & & & & \multicolumn{2}{|c|}{ D7 } & \multicolumn{2}{|c|}{ D8 } & \multicolumn{2}{|c|}{ D9 } \\
\hline & & $n$ & $(\% \pm$ S.E.M. $)$ & $n$ & $(\% \pm$ S.E.M. $)$ & $n$ & $(\% \pm$ S.E.M. $)$ & $n$ & $(\% \pm$ S.E.M. \\
\hline DMSO & 190 & 146 & $77.3 \pm 4.2$ & 28 & $14.9 \pm 1.4$ & 42 & $23.0 \pm 2.7$ & 45 & $24.6 \pm 2.6$ \\
\hline HU-210 & 227 & 180 & $77.9 \pm 3.3$ & 32 & $15.6 \pm 3.5$ & 50 & $23.1 \pm 2.0$ & 56 & $25.0 \pm 1.3$ \\
\hline THC & 240 & 190 & $78.8 \pm 2.7$ & 31 & $13.2 \pm 4.9$ & 51 & $20.8 \pm 5.7$ & 53 & $21.8 \pm 5.8$ \\
\hline
\end{tabular}

Values are the mean \pm S.E.M., $100 \mathrm{mM}$ of HU210 or THC were used, $P>0.05$. 


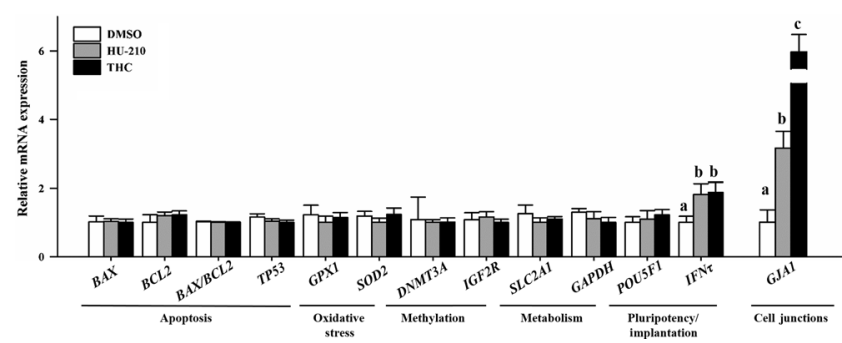

Figure 5 Quantitative real-time PCR (qPCR). Expression patterns of key genes in bovine blastocysts arising from oocytes matured in the presence of the vehicle DMSO (control), HU-210 or THC. Bars with different superscripts indicate a significant difference among treatments $(P<0.05)$.

have a similar effect to EGF or other promotors of maturation (Conti et al. 2012) on the activation of ERK $1 / 2$ both in granulosa cells and in the oocyte. In those oocytes exposed to cannabinoids, meiosis resumption began earlier than in oocytes from the control group. This suggests a potential role for MAPK in the early stages of meiosis resumption in the bovine oocyte model through considerable acceleration of GVBD (Fissore et al. 1996, Kalous et al. 1993). On the contrary, in the mouse oocyte model, cannabinoids do not seem to affect the ERK1/2 phosphorylation status in early maturation stages in which MAPK is not involved (Verlhac et al. 1994, López-Cardona et al. 2014). Effectively, we observed here that after $24 \mathrm{~h}$ maturation, ERK1/2 reached its maximum activity in MIl-arrested bovine oocytes, whereas in the mouse model, cannabinoids were found to reduce the phosphorylation of ERK1/2 (López-Cardona et al. 2014). Taken together, these results indicate differences among mammalian species in the dynamics of the MAPK pathway, as reported by others (Fissore et al. 1996).

In this study, the embryo development rate to the blastocyst stage was not affected by exposure to HU-210 or THC during IVM, although this treatment did have a beneficial effect on the expression of two genes related to embryo quality, IFN $\tau$ and GJA 1. IFN $\tau$ is responsible for the establishment and maintenance of early pregnancy in cattle. Accordingly, bovine blastocysts produced in vivo, in vitro or through ICSI show the differential expression of IFN $\tau$ (Gutierrez-Adan et al. 2004, Arias et al. 2015) with in vitro-produced blastocysts featuring lower relative IFN $\tau$ transcription compared with their in vivo counterparts (Lonergan et al. 2003). Connexin43 (GJA1) is associated with the formation of cell junctions and several reports suggest that its expression is lower in blastocysts produced in vitro vs in vivo (Rizos et al. 2002, Gutierrez-Adan et al. 2004, Tesfaye et al. 2007). Hence, the significantly upregulated expression of both IFN $\tau$ and GJA1 observed here for embryos supplemented with cannabinoids during oocyte maturation suggests that cannabinoids may have improved the quality of those embryos.
In conclusion, our findings indicate that exposure to cannabinoids during the in vitro maturation of oocytes activated AKT and ERK1/2 faster and it is possible that activation could serve to modulate PI3K/AKT and MAPK molecular pathways, probably via CB1 activation, with positive effects on the expression of genes related to embryo quality and no repercussions on the embryo development. These findings have implications for improving IVM in cattle. In addition, the bovine oocyte model emerged as a useful tool for preclinical screening of exogenous cannabinoids targeted at improving the quality of human embryos produced through assisted reproduction techniques.

\section{Declaration of interest}

The authors declare that there is no conflict of interest that could be perceived as prejudicing the impartiality of the research reported.

\section{Funding}

This work was funded by the State Secretariat for Research, Development and Innovation of Spain (A G A: AGL201239652 and D R: AGL2012-37510) and by Grant GIU14/26 from the University of the Basque Country.

\section{Acknowledgements}

A P López-Cardona acknowledges the financial support given by Universidad de Antioquia, COLCIENCIAS, through the Francisco José de Caldas fellowship 512/2010.

\section{References}

Agirregoitia E, Ibarra-Lecue I, Totorikaguena L, Mendoza R, Exposito A, Matorras R, Uriguen L \& Agirregoitia N 2015 Dynamics of expression and localization of the cannabinoid system in granulosa cells during oocyte nuclear maturation. Fertility and Sterility 104 753-760. (doi:10.1016/j.fertnstert.2015.06.013)

Arias ME, Risopatron J, Sanchez R \& Felmer R 2015 Intracytoplasmic sperm injection affects embryo developmental potential and gene expression in cattle. Reproductive Biology 15 34-41. (doi:10.1016/j. repbio.2014.11.001)

Barnes FL, Crombie A, Gardner DK, Kausche A, Lacham-Kaplan O, Suikkari AM, Tiglias J, Wood C \& Trounson AO 1995 Blastocyst development and birth after in-vitro maturation of human primary oocytes, intracytoplasmic sperm injection and assisted hatching. Human Reproduction 10 3243-3247.

Barnes FL, Kausche A, Tiglias J, Wood C, Wilton L \& Trounson A 1996 Production of embryos from in vitro-matured primary human oocytes. Fertility and Sterility 65 1151-1156. (doi:10.1016/S00150282(16)58330-7)

Beker van Woudenberg A, Grollers-Mulderij M, Snel C, Jeurissen N, Stierum R \& Wolterbeek A 2012 The bovine oocyte in vitro maturation model: a potential tool for reproductive toxicology screening. Reproductive Toxicology 34 251-260. (doi:10.1016/j. reprotox.2012.05.098)

Bermejo-Alvarez P, Rizos D, Rath D, Lonergan P \& Gutierrez-Adan A 2010 Sex determines the expression level of one third of the actively expressed genes in bovine blastocysts. PNAS 107 3394-3399. (doi:10.1073/ pnas.0913843107) 
Bermejo-Alvarez P, Rizos D, Lonergan P \& Gutierrez-Adan A 2011 Transcriptional sexual dimorphism during preimplantation embryo development and its consequences for developmental competence and adult health and disease. Reproduction 141 563-570. (doi:10.1530/ REP-10-0482)

Cahill CM, Holdridge SV \& Morinville A 2007 Trafficking of delta-opioid receptors and other G-protein-coupled receptors: implications for pain and analgesia. Trends in Pharmacological Sciences 28 23-31. (doi:10.1016/j.tips.2006.11.003)

Campbell BK, Souza C, Gong J, Webb R, Kendall N, Marsters P, Robinson G, Mitchell A, Telfer EE \& Baird DT 2003 Domestic ruminants as models for the elucidation of the mechanisms controlling ovarian follicle development in humans. Reproduction Supplements 61 429-443.

Carvalho CR, Carvalheira JB, Lima MH, Zimmerman SF, Caperuto LC, Amanso A, Gasparetti AL, Meneghetti V, Zimmerman LF, Velloso LA et al. 2003 Novel signal transduction pathway for luteinizing hormone and its interaction with insulin: activation of Janus kinase/signal transducer and activator of transcription and phosphoinositol 3-kinase/ Akt pathways. Endocrinology 144 638-647. (doi:10.1210/en.2002220706)

Cecconi S, Mauro A, Cellini V \& Patacchiola F 2012 The role of Akt signalling in the mammalian ovary. International Journal of Developmental Biology 56 809-817. (doi:10.1387/ijdb.120146sc)

Conti M, Hsieh M, Zamah AM \& Oh JS 2012 Novel signaling mechanisms in the ovary during oocyte maturation and ovulation. Molecular and Cellular Endocrinology 356 65-73. (doi:10.1016/j.mce.2011.11.002)

Coy P, Grullon L, Canovas S, Romar R, Matas C \& Aviles M 2008 Hardening of the zona pellucida of unfertilized eggs can reduce polyspermic fertilization in the pig and cow. Reproduction 135 19-27. (doi:10.1530/ REP-07-0280)

Cha KY, Han SY, Chung HM, Choi DH, Lim JM, Lee WS, Ko JJ \& Yoon TK 2000 Pregnancies and deliveries after in vitro maturation culture followed by in vitro fertilization and embryo transfer without stimulation in women with polycystic ovary syndrome. Fertility and Sterility $\mathbf{7 3}$ 978-983. (doi:10.1016/S0015-0282(00)00422-2)

Chen J, Torcia S, Xie F, Lin CJ, Cakmak H, Franciosi F, Horner K, Onodera C, Song JS, Cedars MI et al. 2013 Somatic cells regulate maternal mRNA translation and developmental competence of mouse oocytes. Nature Cell Biology 15 1415-1423. (doi:10.1038/ncb2873)

Devane WA, Dysarz Fr, Johnson MR, Melvin LS \& Howlett AC 1988 Determination and characterization of a cannabinoid receptor in rat brain. Molecular Pharmacology 34 605-613.

El-Talatini MR, Taylor AH, Elson JC, Brown L, Davidson AC \& Konje JC 2009a Localisation and function of the endocannabinoid system in the human ovary. PLOS ONE 4 e4579. (doi:10.1371/journal.pone.0004579)

El-Talatini MR, Taylor AH \& Konje JC 2009b Fluctuation in anandamide levels from ovulation to early pregnancy in in-vitro fertilization-embryo transfer women, and its hormonal regulation. Human Reproduction 24 1989-1998. (doi:10.1093/humrep/dep065)

Fissore RA, He CL \& Vande Woude GF 1996 Potential role of mitogenactivated protein kinase during meiosis resumption in bovine oocytes. Biology of Reproduction 55 1261-1270. (doi:10.1095/ biolreprod55.6.1261)

Gervasi MG, Osycka-Salut C, Caballero J, Vazquez-Levin M, Pereyra E, Billi S, Franchi A \& Perez-Martinez S 2011 Anandamide capacitates bull spermatozoa through CB1 and TRPV1 activation. PLoS ONE 6 e16993. (doi:10.1371/journal.pone.0016993)

Gervasi MG, Marczylo TH, Lam PM, Rana S, Franchi AM, Konje JC \& Perez-Martinez S 2013 Anandamide levels fluctuate in the bovine oviduct during the oestrous cycle. PLOS ONE 8 e72521. (doi:10.1371/ journal.pone.0072521)

Gervasi MG, Osycka-Salut C, Sanchez T, Alonso C, Llados C, Castellano L, Franch AM, Villalon M \& Perez-Martinez S 2016 Sperm release from the oviductal epithelium depends on Ca Influx upon activation of CB1 and TRPV1 by anandamide. Journal of Cellular Biochemistry 117 320-333. (doi:10.1002/jcb.25273)

Gonzalez-Robayna IJ, Falender AE, Ochsner S, Firestone GL \& Richards JS 2000 Follicle-Stimulating hormone (FSH) stimulates phosphorylation and activation of protein kinase B (PKB/Akt) and serum and glucocorticoidInduced kinase (Sgk): evidence for A kinase-independent signaling by FSH in granulosa cells. Molecular Endocrinology 14 1283-1300. (doi:10.1210/mend.14.8.0500)
Gutierrez-Adan A \& Pintado B 2000 Effect of flanking matrix attachment regions on the expression of microinjected transgenes during preimplantation development of mouse embryos. Transgenic Research 9 81-89. (doi:10.1023/A:1008926022370)

Gutierrez-Adan A, Rizos D, Fair T, Moreira PN, Pintado B, de la Fuente J, Boland MP \& Lonergan P 2004 Effect of speed of development on mRNA expression pattern in early bovine embryos cultured in vivo or in vitro. Molecular Reproduction and Development 68 441-448. (doi:10.1002/ mrd.20113)

Holm P, Booth PJ, Schmidt MH, Greve T \& Callesen H 1999 High bovine blastocyst development in a static in vitro production system using SOFaa medium supplemented with sodium citrate and myo-inositol with or without serum-proteins. Theriogenology 52 683-700. (doi:10.1016/ S0093-691X(99)00162-4)

Huang J, Yan J, Zhang J, Zhu S, Wang Y, Shi T, Zhu C, Chen C, Liu X \& Cheng J 2012 SUMO1 modification of PTEN regulates tumorigenesis by controlling its association with the plasma membrane. Nature Communications 3 911. (doi:10.1038/ncomms1919)

Kalous J, Kubelka M, Rimkevicova Z, Guerrier P \& Motlik J 1993 Okadaic acid accelerates germinal vesicle breakdown and overcomes cycloheximide- and 6-dimethylaminopurine block in cattle and pig oocytes. Developmental Biology 157 448-454. (doi:10.1006/ dbio.1993.1148)

Kalous J, Kubelka M, Solc P, Susor A \& Motlik J 2009 AKT (protein kinase B) is implicated in meiotic maturation of porcine oocytes. Reproduction 138 645-654. (doi:10.1530/REP-08-0461)

Khatir H, Lonergan P \& Mermillod P 1998 Kinetics of nuclear maturation and protein profiles of oocytes from prepubertal and adult cattle during in vitro maturation. Theriogenology $\mathbf{5 0} 917-929$. (doi:10.1016/S0093691X(98)00196-4)

Levesque JT \& Sirard MA 1995 Effects of different kinases and phosphatases on nuclear and cytoplasmic maturation of bovine oocytes. Molecular Reproduction and Development 42 114-121. (doi:10.1002/ mrd.1080420115)

Lonergan P, Rizos D, Gutierrez-Adan A, Moreira PM, Pintado B, de la Fuente J \& Boland MP 2003 Temporal divergence in the pattern of messenger RNA expression in bovine embryos cultured from the zygote to blastocyst stage in vitro or in vivo. Biology of Reproduction 69 1424-1431. (doi:10.1095/biolreprod.103.018168)

López-Cardona AP, Agirregoitia N, Gutiérrez-Adán A \& Agirregoitia E 2014 Function of CB1 and CB2 during oocyte maturation: importance on fertilization and embryo development in mouse, XV Reunión anual SEIC, Cuenca-España.

Matsuda LA, Lolait SJ, Brownstein MJ, Young AC \& Bonner TI 1990 Structure of a cannabinoid receptor and functional expression of the cloned cDNA. Nature 346 561-564. (doi:10.1038/346561a0)

Mehlmann LM 2013 Losing mom's message: requirement for DCP1A and DCP2 in the degradation of maternal transcripts during oocyte maturation. Biology of Reproduction 88 10. (doi:10.1095/biolreprod.112.106591)

Menezo YJ \& Herubel F 2002 Mouse and bovine models for human IVF. Reproductive BioMedicine Online 4 170-175. (doi:10.1016/S14726483(10)61936-0)

Menezo YJ, Veiga A \& Pouly JL 2000 Assisted reproductive technology (ART) in humans: facts and uncertainties. Theriogenology 53 599-610. (doi:10.1016/S0093-691X(99)00260-5)

Miller MR, Mannowetz N, lavarone AT, Safavi R, Gracheva EO, Smith JF, Hill RZ, Bautista DM, Kirichok Y \& Lishko PV 2016 Unconventional endocannabinoid signaling governs sperm activation via sex hormone progesterone. Science 352 555-559. (doi:10.1126/science.aad6887)

Moussa M, Shu J, Zhang XH \& Zeng F 2015 Maternal control of oocyte quality in cattle "a review". Animal Reproduction Science 155 11-27. (doi:10.1016/j.anireprosci.2015.01.011)

Murray RM, Morrison PD, Henquet C \& Di Forti M 2007 Cannabis, the mind and society: the hash realities. Nature Reviews Neuroscience 8 885-895. (doi:10.1038/nrn2253)

Okumura E, Fukuhara T, Yoshida H, Hanada Si S, Kozutsumi R, Mori M, Tachibana K \& Kishimoto T 2002 Akt inhibits Myt1 in the signalling pathway that leads to meiotic G2/M-phase transition. Nature Cell Biology 4 111-116. (doi:10.1038/ncb741)

Paria BC, Das SK \& Dey SK 1995 The preimplantation mouse embryo is a target for cannabinoid ligand-receptor signaling. PNAS 92 9460-9464. (doi:10.1073/pnas.92.21.9460) 
Peralta L, Agirregoitia E, Mendoza R, Exposito A, Casis L, Matorras R \& Agirregoitia N 2011 Expression and localization of cannabinoid receptors in human immature oocytes and unfertilized metaphase-II oocytes. Reproductive BioMedicine Online 23 372-379. (doi:10.1016/j. rbmo.2011.05.011)

Pertwee RG 2006 The pharmacology of cannabinoid receptors and their ligands: an overview. International Journal of Obesity $\mathbf{3 0}$ (Supplement 1) S13-S18. (doi:10.1038/sj.ijo.0803272)

Revelli A, Massobrio M \& Tesarik J 1998 Nongenomic actions of steroid hormones in reproductive tissues 1. Endocrine Reviews 19 3-17. (doi:10.1210/er.19.1.3)

Rizos D, Lonergan P, Boland MP, Arroyo-Garcia R, Pintado B, de la Fuente J \& Gutierrez-Adan A 2002 Analysis of differential messenger RNA expression between bovine blastocysts produced in different culture systems: implications for blastocyst quality. Biology of Reproduction $\mathbf{6 6}$ 589-595. (doi:10.1095/biolreprod66.3.589)

Santos RR, Schoevers EJ \& Roelen BA 2014 Usefulness of bovine and porcine IVM/IVF models for reproductive toxicology. Reproductive Biology and Endocrinology 12 117. (doi:10.1186/1477-7827-12-117)

Schmitt A \& Nebreda AR 2002 Signalling pathways in oocyte meiotic maturation. Journal of Cell Science 115 2457-2459.

Schuel H, Burkman LJ, Lippes J, Crickard K, Forester E, Piomelli D \& Giuffrida A 2002 N-Acylethanolamines in human reproductive fluids. Chemistry and Physics of Lipids 121 211-227. (doi:10.1016/S00093084(02)00158-5)

Sirard MA, Richard F, Blondin P \& Robert C 2006 Contribution of the oocyte to embryo quality. Theriogenology 65 126-136. (doi:10.1016/j. theriogenology.2005.09.020)

Su YQ, Denegre JM, Wigglesworth K, Pendola FL, O'Brien MJ \& Eppig JJ 2003 Oocyte-dependent activation of mitogen-activated protein kinase (ERK1/2) in cumulus cells is required for the maturation of the mouse oocyte-cumulus cell complex. Developmental Biology 263 126-138. (doi:10.1016/S0012-1606(03)00437-8)

Tesfaye D, Lonergan P, Hoelker M, Rings F, Nganvongpanit K, Havlicek V, Besenfelder U, Jennen D, Tholen E \& Schellander K 2007 Suppression of connexin 43 and E-cadherin transcripts in in vitro derived bovine embryos following culture in vitro or in vivo in the homologous bovine oviduct. Molecular Reproduction and Development 74 978-988. (doi:10.1002/mrd.20678)

Tomek W \& Smiljakovic T 2005 Activation of Akt (protein kinase B) stimulates metaphase I to metaphase II transition in bovine oocytes. Reproduction 130 423-430. (doi:10.1530/rep.1.00754)

Van Hoeck V, Sturmey RG, Bermejo-Alvarez P, Rizos D, GutierrezAdan A, Leese HJ, Bols PE \& Leroy JL 2011 Elevated non-esterified fatty acid concentrations during bovine oocyte maturation compromise early embryo physiology. PLOS ONE 6 e23183. (doi:10.1371/journal. pone.0023183)

Verlhac MH, Kubiak JZ, Clarke HJ \& Maro B 1994 Microtubule and chromatin behavior follow MAP kinase activity but not MPF activity during meiosis in mouse oocytes. Development 120 1017-1025.

Wang H, Matsumoto H, Guo Y, Paria BC, Roberts RL \& Dey SK 2003 Differential G protein-coupled cannabinoid receptor signaling by anandamide directs blastocyst activation for implantation. PNAS $\mathbf{1 0 0}$ 14914-14919. (doi:10.1073/pnas.2436379100)

Wang H, Guo Y, Wang D, Kingsley PJ, Marnett LJ, Das SK, DuBois RN \& Dey SK 2004 Aberrant cannabinoid signaling impairs oviductal transport of embryos. Nature Medicine 10 1074-1080. (doi:10.1038/nm1104)

Wayne CM, Fan HY, Cheng X \& Richards JS 2007 Follicle-stimulating hormone induces multiple signaling cascades: evidence that activation of Rous sarcoma oncogene, RAS, and the epidermal growth factor receptor are critical for granulosa cell differentiation. Molecular Endocrinology 21 1940-1957. (doi:10.1210/me.2007-0020)

Received 19 February 2016

First decision 11 March 2016

Revised manuscript received 22 August 2016

Accepted 1 September 2016 